\title{
An unsolved issue: utility of implantable loop recorder monitoring in cryptogenic stroke patients
}

\author{
Gulmira Kudaiberdieva ${ }^{1,2} \cdot$ Bulent Gorenek $^{3}$
}

Received: 5 March 2019 / Accepted: 15 March 2019 / Published online: 2 May 2019

c) Springer-Verlag GmbH Germany, part of Springer Nature 2019

Sirs:

We read with interest the recent paper published in Clinical Research in Cardiology on ECG monitoring with implantable loop recorder (ILR) in patients with cryptogenic stroke-retrospective analysis of TRACK AF study [1]. Authors demonstrated detection of atrial fibrillation (AF) in $19.1 \%$ of patients with cryptogenic stroke after median time of $10.7 \pm 11.4$ months. Authors underline use of ILR for AF detection in their paper. However, the routine use of ILR monitoring is not clear yet. According to the recent consensus document of the European Heart Rhythm Association chaired by Bulent Gorenek [2] "outside of research context patients with cryptogenic stroke may not receive an ILR". The TF members agreed on that although implantable monitors could be utilized for AF detection after cryptogenic stroke, this strategy has not been shown to have clinical utility in regard to future stroke prevention and its cost-effectiveness compared with an empiric anticoagulation strategy remains speculative given substantial expense of the devices. The important issue is proximity of detected AF episode and stroke event; however, there was no temporal relation of atrial tachyarrhythmias and stroke [3].

More randomized prospective studies are needed to clarify role of implantable loop recorder monitoring in cryptogenic stroke patients.

A comment to this article is available at https://doi.org/10.1007/ s00392-019-01460-8.

This comment refers to the article available at https://doi. org/10.1007/s00392-018-1358-4.

Gulmira Kudaiberdieva

mygk2017@usa.net

1 Adana, Turkey

2 CPONI, Bishkek, Kyrgyzstan

3 Department of Cardiology, Medical Faculty, Eskisehir Osmanagazi University, Eskisehir, Turkey
Gulmira Kudaiberdieva

Member, EHRA Task Force on device-detected subclinical atrial tachyarrhythmias

Bulent Gorenek

Chair, EHRA Task Force on device-detected subclinical atrial tachyarrhythmias

\section{References}

1. Bettin M, Dechering D, Kochhäuser S et al (2018) Extended ECG monitoring with an implantable loop recorder in patients with cryptogenic stroke: time schedule, reasons for explantation and incidental findings (results from the TRACK-AF trial). Clin Res Cardiol. https://doi.org/10.1007/s00392-018-1358-4

2. Gorenek B, Bax J, Boriani G et al (2017) Device-detected subclinical atrial tachyarrhythmias: definition, implications and management - an European Heart Rhythm Association (EHRA) consensus document, endorsed by Heart Rhythm Society (HRS), Asia Pacific Heart Rhythm Society (APHRS) and Sociedad Latinoamericana de Estimulación Cardíaca y Electrofisiología (SOLEACE). Europace 19:1556-1578

3. Martin DT, Bersohn MM, Waldo AL et al (2015) Randomized trial of atrial arrhythmia monitoring to guide anticoagulation in patients with implanted defibrillator and resynchronization devices. Eur Heart J 36:1660-1668 